Oralidad-es

REVISTA DE LA RED

IBEROAMERICANA DE ESTUDIOS

SOBRE ORALIDAD

\title{
Editorial volumen 5 Oralidad-es
}

Juan Gabriel Araya-Grandón

Correo: jaraya@ubiobio.cl

Universidad del Bío-Bío, Chile

José Gabriel Brauchy

jgb214@nyu.edu

Universidad del Bío-Bío, Chile

Alejandra Cristina Hernández

alhernan@ubiobio.cl

Universidad del Bío-Bío, Chile

Araya-Grandón, J. G., Brauchy, J. G. \& Hernández, A. C. (2019). Editorial volumen 5 Oralidad-es. Oralidad-es, 5, 1-3. https://revistaoralidad-es.com/index.php/ro-es/article/view/117/86

(C) (i) 
El volumen 5 de la Revista Oralidades concentra seis artículos, tres de ellos enmarcados en el género research paper, dos en el género ensayo de reflexión y uno que presenta una entrevista, los que dan cuenta tanto de la discusión de la oralidad en el espacio de formación del profesorado como el ejercicio de la oralidad en la práctica docente.

Respecto de los trabajos enmarcados en el género research paper, el primer artículo, "Lo entrañable del habla popular" de Amanda Betancourt Arango aborda la oralidad desde un punto de vista afectivo para destacar la expresividad y cercanía del habla popular. Mediante un triple enfoque el artículo aborda, en primer lugar, el sonido como hecho acústico y su vehículo, la voz. En segundo lugar, con algún detalle, los suprasegmentos en cuanto le brindan al hablante las posibilidades para el manejo de la voz, tanto desde el punto de vista funcional, vale decir, del significado, como del puramente expresivo, con infinidad de matices aplicables a cualquier situación de intercambio verbal. Y en una tercera instancia se contempla el aspecto pragmático, el uso, propiamente dicho. Se trata, claro está, de una distinción metodológica, no de fondo, porque en el $2^{\circ}$ apartado los aspectos contemplados también revisten, en sentido estricto, tal carácter.

El segundo artículo titulado, "Tendencias temáticas e investigativas de la Red iberoamericana de estudios sobre la oralidad y sus aportes a la formación docente" presentado por Marleny Hernández Rincón y Mirta Yolima Gutiérrez-Ríos revisa las tendencias temáticas e investigativas de la oralidad en Iberoamérica. El artículo lleva a cabo una revisión bibliográfica de experiencias pedagógicas e investigativas presentadas en los congresos de la Red iberoamericana de estudios sobre la oralidad. Bajo el análisis de 153 ponencias publicadas en las memorias de siete congresos realizados en Colombia, España y México entre 2011 y 2018, el artículo establece dos tendencias: la primera, relacionada con la oralidad como campo de estudio y la segunda, referida a la oralidad académica como eje de desarrollo educativo y profesional.

El tercer trabajo, "Oralidad artística: arte performativa y 'desocultamiento del Ser' en la era de la postmodernidad” de Luciana Benítez Schaefer explica la vigencia e importancia de las prácticas orales artísticas a partir de la conceptualización de la performance oral como síntesis de dos elementos opuestos, pero complementarios: la evanescencia propia del habla y la necesidad ontológica de la "verdad" (en el sentido fenomenológico del término). El artículo remite al concepto de "universalidad" en una era postmoderna, donde ambas nociones tienden a ser cuestionadas. Desde una perspectiva dinámica del lenguaje como juego y de la comunicación como proceso que incluye elementos verbales y no verbales, esta investigación promueve la práctica de la oralidad como recurso para asimilar y comprender el universo cultural que nos precede y nos rodea.

En relación con los artículos enmarcados en el género ensayo de reflexión, el primero de ellos, "Tradición oral: patrimonio inmaterial de los pueblos indígenas que la escuela no cubre" que presenta Ma. Regina González Díaz nos invita a repensar los derechos lingüísticos de las comunidades mapuche-pehuenches localizadas en la zona sur de Chile, Alto Biobío. Los hallazgos encontrados a través de entrevistas y revisión de documentos oficiales como programas de estudio del sistema escolar nacional, son la evidencia que apoyan la tesis de su reflexión: los organismos de educación no cubren los requerimientos lingüísticos de los pueblos originarios, lo que invitaría a considerar la posibilidad de crear un currículo cultural mapuche pehuenche, en el entendido que la oralidad es depositaria de la identidad del grupo y forma parte del patrimonio inmaterial universal.

El segundo artículo titulado "La opacidad de la oralidad en el aula de clase: un reto en la docen- 
cia” que presentan Sandra Patricia Tafur Muñoz y Nelsy Jhoanní Armesto Argüelles, apunta a examinar el desarrollo de la oralidad en el aula de clases desde una perspectiva lingüístico-discursiva y pedagógico e investigativo destacando el impacto que ello conlleva en el proceso formativo del estudiante. La apuesta de este ensayo se enfoca en la investigación pedagógica de las actividades discursivas de la lengua y el análisis crítico del discurso (ACD), lo que contribuye a teorizar las relaciones de poder en el aula.

Finalmente, en el género entrevista, Lizbeth Alejandra Gómez presenta una entrevista realizada al profesor Gastón Salamanca Gutiérrez, quien es doctor en lingüística de la Universidad de Concepción en Chile. Ha publicado artículos sobre el español hablado en Chile y algunos centrados en las lenguas mapundungún y el chedungún, entre otros. La entrevista se centra en sus trabajos y reflexiones acerca de la importancia que tienen en el área de la lingüística y la oralidad, en la formación de docentes y en la enseñanza de estos temas.

El equipo que participó en la construcción de este volumen destaca la discusión de la oralidad en el espacio formación del profesorado y el ejercicio de la oralidad en la práctica docente como un aporte a un debate abierto. 